NASA Technical Memorandum 102477

\title{
A New Rectangular Waveguide to Coplanar Waveguide Transition
}

George E. Ponchak

Lewis Research Center

Cleveland, Ohio

and

Rainee N. Simons

Case Western Reserve University

Cleveland, Ohio

Prepared for the

1990 IEEE MTT-S International

Microwave Symposium

Dallas, Texas, May 8-10, 1990 


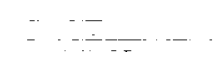
$=\ldots$
$=$

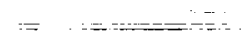
$\therefore==$ 


\section{A NEW RECTANGULAR WAVEGUIDE TO COPLANAR WAVEGUIDE TRANSITION}

George E. Ponchak

NASA Lewis Research Center

Cleveland, Ohio 44135

\section{ABSTRACT}

A new rectangular waveguide to coplanar waveguide transition is described. The transition uses a ridge in one of the broad walls of the wavegulde and a nonradiating slot in the opposite wall to split and rotate the electromagnetic fields of the rectangular waveguide TElO mode into the $\mathrm{CPW}$ fields.

\section{INTROOUCTION}

Coplanar wavegutde (CPW) is an attractive transmission line for microwave integrated circuits since the ground planes are on the same side of the substrate as the conducting strip (1). This permits the integration of both serles as well as shunt circutt elements without the need for back side processing and via holes. A second important advantage of CPW which has recently emerged is in the design of microwave probes for on-wafer characterization of field effect transistors and for fast, inexpensive evaluation of microwave integrated circuits (2).

In order to fully utilize these advantages, transitions between $C P W$ and other microwave transmission media are required. A coaxial connector to CPW transition in which the center pin and the ground connection of the coaxial connector make contact with the CPW center strip and ground planes respectively has been demonstrated at $18 \mathrm{GHz}$ (3). By reducing the dlameter of the coaxial connector, the upper frequency of these transitions has been extended to $50 \mathrm{GHz}$. Further reduction of the coaxlal connector dimensions to increase the frequency of operation may be limited by the fragility of the connectors. Also, millimeter wave sources use rectangular wavegulde at the output ports. Therefore, there is a need to develop rectangular wavegulde to CPW transitions for applications at $V$-Band ( 50 to $75 \mathrm{GHz}$ ) and $W$-Band ( 75 to $110 \mathrm{GHz}$ ).

A waveguide to CPW transition has been reported by Bellantoni, et al. (4). The transition uses a finline taper to concentrate the electric

* NASA Resident Research Assoclate at Lewis Research Center (work funded by NASA Grant NAG3-816).
Rainee N. Simons*

Case Western Reserve University

Cleveland, Ohio 44106

fields and a whe bond to split the electric currents between the two ground planes. The difficulty with the design is positioning the wire bond such that the two slots are excited in squal magnitude and phase. A further difflculty with finline transitions is the occurrence of resonances created by the transition $(4,5)$. This paper presents the design and characteristics of a new rectangular waveguide to CPW transition which uses a ridge in one of the broad walls of the waveguide and a nonradiating slot in the opposite wall. This arrangement transforms the rectangular wavegulde TE10 mode into the CPW mode with equal magnitude and phase excitation of the slots. The transition is capable of provlding full waveguide bandwidth.

\section{TRANSITION DESIGN}

Figure 1 is a schematic of the transition. The printed circuit board shown in Fig. I(a) forms the bottom wall of the rectangular waveguide. On this printed circuit board, a nonradiating slot is etched which gradually tapers to a width equal to $S+2 W$, where $S$ and $W$ are the width of the CPW center strip and slot, respectively. The cosine tapered ridge shown in Fig. I(b) protrudes from the top wall of the wavegulde and extends down to the printed circult board metalization at the end of the taper. The ridge width is matched to the width of the center strip conductor, 5 , of the $C P W$. The electric field distribution at cross sectional planes along the transtion ts lliustrated in Fig. 2. One can easily visualize that the ridge and the nonradiating slot gradually split the electromagnetic fieids of the TElO waveguide mode and rotate them through $90^{\circ}$ to match the flelds of the CPW.

\section{TEST RESULTS FOR $K$ BAND TRANSITION}

A transition has been designed for $K$ band. The printed circult portion of the transition has been fabricated on a $0.125 \mathrm{in}$. thick 5880 RT/Ouroid substrate with single sided copper cladding. The ridged waveguide portion of the transition is copper. The cosine taper is $1.5 \mathrm{in.}$ long or approximately $1.5 \lambda_{g}$ at the center frequency. The $S$ and $W$ of the CPW are 0.032 and $0.008 \mathrm{in}$. respectively yielding a $75 \Omega$ transmission iline. For testing. the two transitions were connected back to back through a $0.8 \mathrm{in}$. length of CPW transmission 1 ine. The characteristics for this transition are shown in Fig. 3. The return loss is greater than 11 dB 


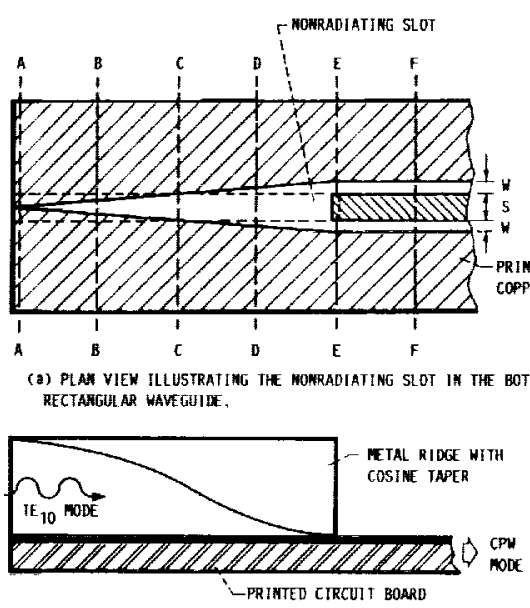

(b) LOMGI TUDIHAL VIEW ILEUSTRATING THE COSINE IAPERED WETML RIGGE.

FIGURE 1. - SCHEMATIC OF THE TRANSITION.
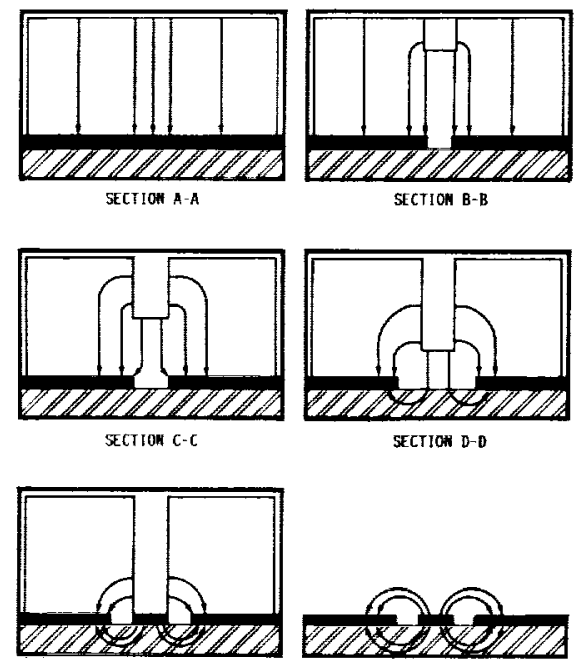

TECTION E-E

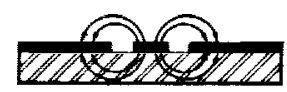

FIGURE 2. - ELECTRIC FIELD DISTRIBUTION AT VARIOUS CROSS-SECTIONS ALONG THE TRANSITION.

across the band. The average insertion loss for the back-to-back transitions is $1.75 \mathrm{~dB}$ with $0.25 \mathrm{~dB}$ ripple.

\section{CONCLUSIONS}

A new rectangular waveguide to $C P W$ transition has been developed with full waveguide bandwidth. This transition should permit the use of CPW based circults in the millimeter wave frequency range and the development of microwave probes above $50 \mathrm{GHz}$ for fast and inexpensive testing of the millimeter wave circuits.

\section{REFERENCES}

(1) C.P. Wen, "Coplanar Wavegulde: A Surface Strip Transmission Line Sultable for Nonreciprocal Gyromagnetic Device Applications," IEEE Trans. Microwave Theory Tech. vol. MTT-17, no. 12, pp. 1087-1090, 1969.

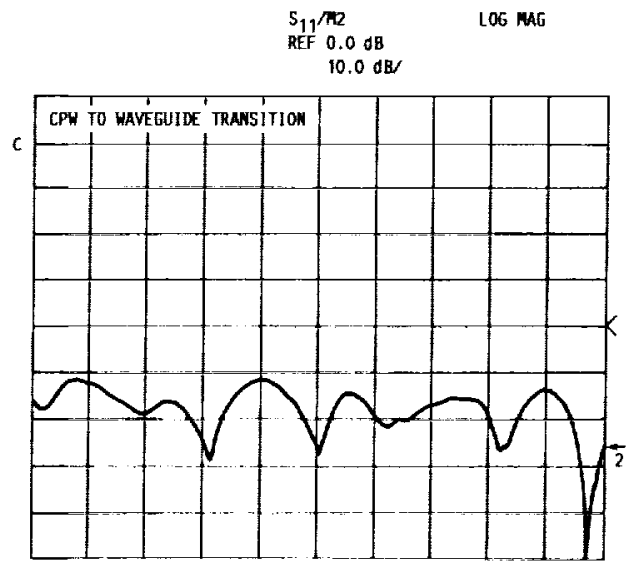

(a) IMPUT RETURM LOSS AS FEASURED AT THE WAVEGUIDE PORT.

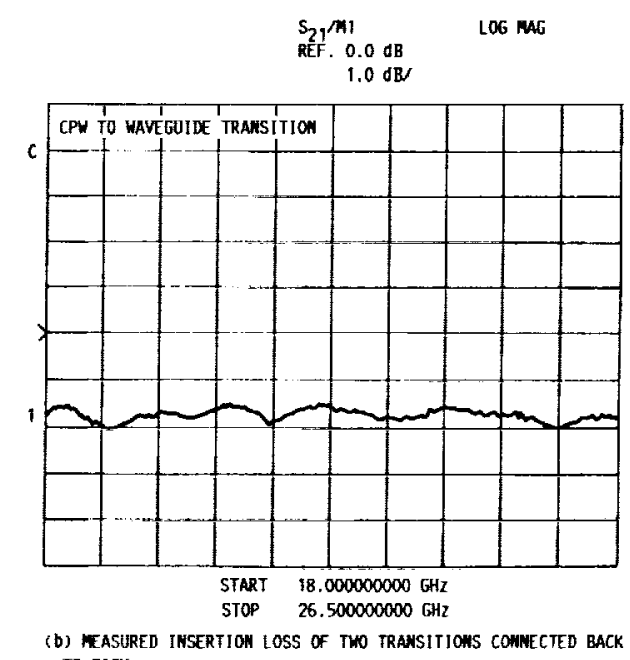

T IGURE 3.

(2) K.E. Jones, E.W. Strid, and K.R. Gleason, "min-Wave Wafer Probes Span O to $50 \mathrm{GHz}$," Mfcrowave J., vol. 30, no. 4, pp. 177-i83. 1987.

(3) M. Houdart and C. Aury, "Various Excitation of Coplanar Waveguide," in IEEE MTT-S International Microwave Symposfum Digest. 1979 , pp. $116-118$.

(4) J.V. Bellantoni, R.C. Compton, and H.M. Levy, "A New W-Band Coplanar Wavegulde Text Fixture," in IEEE MTT-S International MICrowave Symposium Dlgest. 1989, pp. 1203-1204.

(5) G. Begemann "An X-Band Balanced Fin-Line Mixer," IEEE Trans. Microwave Theory Tech., vol. MTT-26, no. 12, pp. 1007-1011, 1978. 


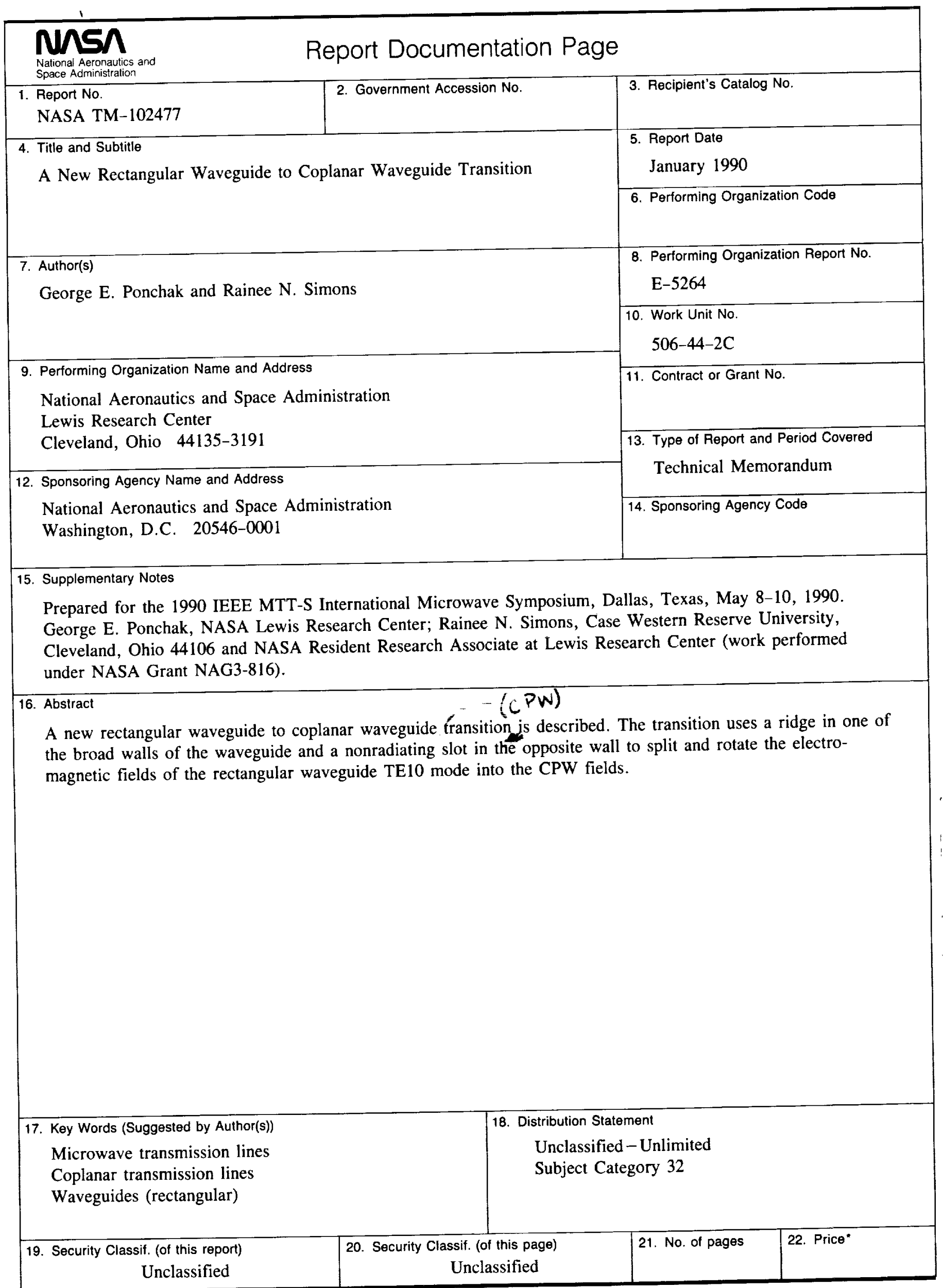


